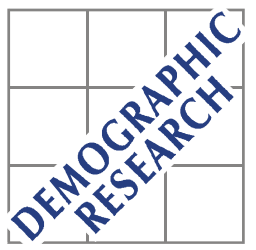

Demographic Research a free, expedited, online journal of peer-reviewed research and commentary in the population sciences published by the Max Planck Institute for Demographic Research Konrad-Zuse Str. 1, D-18057 Rostock · GERMANY www.demographic-research.org

DEMOGRAPHIC RESEARCH

VOLUME 14, ARTICLE 22, PAGES 541-574

PUBLISHED 30 JUNE 2006

http://www.demographic-research.org/Volumes/Vol14/22/

DOI: 10.4054/DemRes.2006.14.22

Research Article

Modelling the demographic impact of HIV/AIDS in South Africa and the likely impact of interventions

Leigh F. Johnson

Rob E. Dorrington

(C) 2006 Max-Planck-Gesellschaft. 


\section{Table of Contents}

$1 \quad$ Introduction $\quad 542$

2 Method 543

2.1 Modelling of sexual behaviour $\quad 543$

2.2 Modelling of HIV survival 547

$2.3 \quad$ Modelling of sexual transmission 550

$2.4 \quad$ Modelling vertical transmission and paediatric HIV survival 552

2.5 Modelling of prevention and treatment programmes 553

$\begin{array}{lll}2.6 & \text { Calibration } & 555\end{array}$

3 Results $\quad 556$

4 Discussion $\quad 562$

5 Acknowledgements $\quad 565$

References $\quad 566$ 


\title{
Modelling the demographic impact of HIV/AIDS in South Africa and the likely impact of interventions
}

\author{
Leigh F. Johnson ${ }^{1}$ \\ Rob E. Dorrington ${ }^{2}$
}

\begin{abstract}
This paper describes an approach to incorporating the impact of HIV/AIDS and the effects of HIV/AIDS prevention and treatment programmes into a cohort component projection model of the South African population. The modelled HIV-positive population is divided into clinical and treatment stages, and it is demonstrated that the age profile and morbidity profile of the HIV-positive population is changing significantly over time. HIV/AIDS is projected to have a substantial demographic impact in South Africa. Prevention programmes - social marketing, voluntary counselling and testing, prevention of mother-to-child transmission and improved treatment for sexually transmitted diseases - are unlikely to reduce AIDS mortality significantly in the short term. However, more immediate reductions in mortality can be achieved when antiretroviral treatment is introduced.
\end{abstract}

\footnotetext{
${ }^{1}$ Centre for Actuarial Research, Leslie Commerce Building, University of Cape Town, Private Bag, Rondebosch 7701, South Africa. Tel: +2721

650 5761, Fax:+27 21689 7580. E-mail: ljohnson@commerce.uct.ac.za.
}

${ }^{2}$ Centre for Actuarial Research, University of Cape Town. 


\section{Introduction}

South Africa is one of the few African countries with nationally representative HIV prevalence data and good vital registration data (Department of Health 2004; Bradshaw et al. 2004). However, these data cannot provide planners with a direct measure of the demographic impact of HIV/AIDS or an indication of the likely future evolution of the epidemic. For this, mathematical models, calibrated to these data, are necessary. These models, if appropriately constructed, can also be used to assess the likely effect of different prevention and treatment programmes, as well as likely needs for treatment and orphan care, and are therefore an important tool in policy formulation.

A large number of mathematical models have been developed to simulate the impact of HIV/AIDS and the likely effect of prevention and treatment programmes. These models can be classified into two broad groups: individual-based stochastic simulation models, which randomly generate events such as infection and death for each individual in the population; and deterministic models, which typically divide the population into cohorts of individuals, and compute average numbers of events in each cohort on the assumption that all individuals in a cohort share the same characteristics.

Of the stochastic models that have been developed, most have focussed on simulating the effects of HIV prevention rather than treatment (Korenromp et al. 2000; Van der Ploeg et al. 1998; Bracher, Santow and Cotts Watkins 2004; Robinson et al. 1995). Because of the heavy computational requirements associated with individualbased simulation, populations simulated are typically limited in size to 10000 to 20000 individuals. This results in a significant amount of stochastic variation, which makes it difficult to calibrate the model to HIV prevalence and mortality data (Korenromp et al. 2000). In addition, these models require an extensive range of assumptions as input.

Deterministic models tend to be used for larger populations and in situations where data for setting assumptions are limited. Many of these models have been used to illustrate the differences between the effects of HIV prevention and treatment programmes (Salomon et al. 2005; Stover et al. 2002; Nagelkerke et al. 2002). However, many of these models are based on very broad age divisions of the population, which makes them inappropriate for projecting the population over long periods. In some cases, the results of these simple deterministic models have been incorporated into cohort component projection models such as DemProj (Stover 2004), in an attempt to estimate the demographic impact of HIV/AIDS more accurately. However, Heuveline (2003) identifies a number of problems with this approach, including failure to allow for changes in the age profile of HIV cases over the course of the epidemic, difficulties in incorporating the effect of HIV on fertility, and difficulties in establishing parameters for a cohort component projection model in a hypothetical 'no AIDS' scenario. 
The ASSA2002 AIDS and Demographic model is a combined cohort component projection and HIV/AIDS model, developed by the Actuarial Society of South Africa to estimate the impact of HIV/AIDS in South Africa. The basic structure of the earlier ASSA2000 version of the model has been described previously (Dorrington 2000). The objective of this paper is to describe how the basic cohort component projection model has been extended to model the demographic impact of HIV/AIDS, to describe how HIV prevention and treatment programmes are modelled, and to demonstrate the significance of these prevention and treatment programmes in demographic terms.

\section{Method}

The ASSA2002 model was developed from an earlier version of the model, ASSA2000, which did not allow for the effects of prevention and treatment programmes. It is assumed that the epidemic is started by the 'importing' of a number of infected individuals in 1985, a few years prior to the first reports of AIDS cases in the heterosexual population. The epidemic is modelled as being spread by heterosexual intercourse and mother-to-child transmission. Age-specific assumptions about the population profile in 1985, fertility, non-AIDS mortality and international migration are based on analyses of the 1970, 1996 and 2001 censuses, vital registration data from 1985 onwards and the 1998 Demographic and Health Survey (DHS), and are not described here.

The model has been programmed both in Excel/VBA and in Visual $\mathrm{C}++$, and the Excel/VBA version is freely available online (Actuarial Society of South Africa 2004) . $^{3}$ A user guide for the model (Dorrington, Johnson and Budlender 2004) is also available online. A separate model, which makes use of output from the AIDS and Demographic model, has been developed to estimate numbers of orphans from the ASSA2002 outputs, and is described elsewhere (Johnson and Dorrington 2001).

\subsection{Modelling of sexual behaviour}

Individuals are assumed to be at risk of acquiring HIV through heterosexual contact between the ages of 14 and 59. Within this age band, individuals are split into four 'risk groups': a 'PRO' group, which represents sex workers and their frequent clients; a 'STD' group, which represents individuals who are regularly infected with sexually transmitted diseases (STDs) although not frequently engaging in commercial sex; a

${ }^{3}$ The version of the ASSA2002 model used in this paper is the ASSA2002 'lite' model, number 040701. 
'RSK' group, consisting of individuals who are at risk of HIV infection although not regularly infected with other STDs; and a 'NOT' group, comprising individuals who are not at risk of infection (either because they are not sexually active or because they are in long-term mutually monogamous relationships). The assumed relative sizes of these risk groups and their sexual behaviour characteristics are shown in Table 1.

The relative sizes of the risk groups are assumed to be the same for males and females, as are the relative frequencies of condom usage in each risk group. Male preferences regarding the risk group of their female partners, as well as average annual numbers of female partners, are determined to be consistent with the assumptions for females. Average fertility rates are assumed to apply to women in the RSK group, while women in the PRO and STD groups have fertility rates that are lower than the average by $60 \%$ and $30 \%$ respectively. This allows for the effects of higher contraceptive usage and STD incidence in the PRO and STD groups.

Rates of condom use are assumed to be higher in the PRO and STD groups, as condoms tend to be used more frequently in short-term casual relationships (Van der Ryst et al. 2001; Williams et al. 2000; Department of Health 1999). The condom usage adjustment factors in Table 1 represent the factor by which the average age-specific

Table 1: $\quad$ Characteristics of risk groups

\begin{tabular}{|c|c|c|c|c|c|c|c|c|}
\hline & \multicolumn{4}{|c|}{ Female risk group } & \multicolumn{4}{|c|}{ Male risk group } \\
\hline & PRO & STD & RSK & NOT & PRO & STD & RSK & NOT \\
\hline $\begin{array}{l}\% \text { of } 25-59 \text { population in } \\
\text { risk group in } 1985\end{array}$ & $1 \%$ & $20 \%$ & $23 \%$ & $56 \%$ & $1 \%$ & $20 \%$ & $23 \%$ & $56 \%$ \\
\hline $\begin{array}{l}\text { Average annual number } \\
\text { of new partners }\end{array}$ & 250 & 12 & 1 & - & $233^{*}$ & $13^{*}$ & $1^{*}$ & - \\
\hline \multicolumn{9}{|l|}{$\%$ of new partners in } \\
\hline PRO group & 0.75 & 0.2 & 0 & - & $0.8^{*}$ & $0.26^{*}$ & 0 & - \\
\hline STD group & 0.25 & 0.75 & 0.4 & - & $0.2^{*}$ & $0.71^{*}$ & $0.47^{*}$ & - \\
\hline RSK group & 0 & 0.05 & 0.6 & - & 0 & $0.04^{*}$ & $0.53^{*}$ & - \\
\hline \multicolumn{9}{|l|}{$\begin{array}{l}\text { Average \# coital acts per } \\
\text { partnership if partner is in }\end{array}$} \\
\hline PRO group & 1 & 3 & - & - & 1 & 1 & - & - \\
\hline STD group & 1 & 13 & 50 & - & 3 & 13 & 45 & - \\
\hline RSK group & - & 45 & 95 & - & - & 50 & 95 & - \\
\hline $\begin{array}{l}\text { Condom usage } \\
\text { adjustment factor }\end{array}$ & 2 & 1.5 & 1 & - & 2 & 1.5 & 1 & - \\
\hline Fertility adjustment factor & 0.4 & 0.7 & 1 & $1.12^{\dagger}$ & - & - & - & - \\
\hline
\end{tabular}


rates of condom usage are multiplied to obtain age-specific condom usage rates in each risk group. The average age-specific rates for 1998 were set to be the same as those recorded in the 1998 DHS, and are shown in Table 2. Frequency of condom use appears to have increased substantially in recent years (Human Sciences Research Council 2002; Reproductive Health Research Unit 2004), and it is assumed that this is the result of social marketing programmes. In the absence of these social marketing programmes, it is assumed that condom usage would have remained constant at half the level observed in 1998, in all years.

Table 2: $\quad$ Age-specific behavioural assumptions

\begin{tabular}{|c|c|c|c|c|c|}
\hline \multirow{2}{*}{ Age group } & \multicolumn{2}{|c|}{ Average rate of condom usage } & \multirow{2}{*}{$\begin{array}{l}\text { \% sexually } \\
\text { experienced }\end{array}$} & \multicolumn{2}{|c|}{ Age of male partners } \\
\hline & 1985 & $1998^{*}$ & & Average & Variance \\
\hline $15-19$ & $9.8 \%$ & $19.6 \%$ & $46 \%$ & 24.31 & 19.80 \\
\hline $20-24$ & $7.2 \%$ & $14.4 \%$ & $90 \%$ & 28.84 & 25.24 \\
\hline $25-29$ & $3.8 \%$ & $7.6 \%$ & $100 \%$ & 32.95 & 49.43 \\
\hline $30-34$ & $3.3 \%$ & $6.6 \%$ & $100 \%$ & 37.63 & 55.10 \\
\hline $35-39$ & $1.5 \%$ & $3.0 \%$ & $100 \%$ & 42.69 & 70.99 \\
\hline $40-44$ & $1.5 \%$ & $3.0 \%$ & $100 \%$ & 47.04 & 66.86 \\
\hline $45-49$ & $1.5 \%$ & $3.0 \%$ & $100 \%$ & 51.45 & 56.05 \\
\hline $50-54$ & $1.5 \%$ & $3.0 \%$ & $100 \%$ & $55.86^{\dagger}$ & $45.24^{\dagger}$ \\
\hline $55-59$ & $1.5 \%$ & $3.0 \%$ & $100 \%$ & $60.27^{\dagger}$ & $34.43^{\dagger}$ \\
\hline
\end{tabular}

* Allowing for the effect of social marketing programmes. ${ }^{\dagger}$ Extrapolated from estimates at younger ages

Individuals become sexually active between the ages of 13 and 25 . At age 14, it is assumed that $10 \%$ of individuals are sexually experienced, and $12 \%$ of the remainder are assumed to become sexually experienced in the next year. The annual probability of becoming sexually experienced is assumed to increase linearly with respect to age, until all individuals are sexually experienced at age 25 . These assumptions were set to produce rates of sexual experience consistent with those observed in surveys (Reproductive Health Research Unit 2004; Department of Health 1999), and are shown in Table 2. The same sexual debut assumptions are used for males and females, as surveys do not suggest that there is a significant difference in sexual experience between males and females at young ages (Williams et al. 2000; Reproductive Health Research Unit 2004). Individuals remain in the NOT group until they become sexually experienced, after which they either remain in the NOT group or get moved into the other risk groups. The model assumes that people do not change risk group after sexual debut. 
Although individuals cannot move between risk groups after sexual debut, allowance is made for rates of partnership formation and coital frequencies to vary with age. For females, a sexual activity index is constructed using the formula

$$
S_{x}=\sqrt{\frac{46(x-13) \exp \left(-0.005(x-13)^{2}\right)}{\sum_{u=14}^{59}(u-13) \exp \left(-0.005(u-13)^{2}\right)}}
$$

where $S_{x}$ is the multiple by which the average number of partners and the average number of coital acts per partnership increases at age $x$. The shape parameter $(0.005)$ and position parameter (13) were set at levels that ensured patterns of HIV prevalence by age were as far as possible consistent with those observed in surveys (Department of Health 2004). The mean age of male partners and the variance of male partner ages were estimated from the 1998 DHS, for each five-year age band, and are shown in Table 2. For a woman aged $x$, the distribution of male partner ages, $f(y \mid x)$, is assumed to be gamma, with mean and variance determined from the values in Table 2 . Thus,

$$
f(y \mid x)=\int_{y-1}^{y} \frac{\lambda^{\alpha}(u-13)^{\alpha-1} \exp (-\lambda(u-13))}{\Gamma(\alpha)} d u .
$$

For a man aged $y$, the sexual activity index is calculated using the formula

$$
S_{y}^{*}=\sqrt{46 \sum_{x=14}^{59} f(y \mid x) S_{x}^{2} / \sum_{u=14}^{59} S_{u}^{2}},
$$

and the proportion of female partners aged $x$ is calculated as

$$
f^{*}(x \mid y)=f(y \mid x) \frac{S_{x}^{2} / \sum_{u=14}^{59} S_{u}^{2}}{S_{y}^{* 2} / \sum_{u=14}^{59} S_{u}^{* 2}} .
$$




\subsection{Modelling of HIV survival}

In the absence of treatment and other interventions, adult HIV survival is modelled using a four-stage model of HIV disease progression, with the four stages corresponding to the four stages of the WHO Clinical Staging System (WHO International Collaborating Group for the study of the WHO Staging System 1993). The effect of highly active antiretroviral treatment (HAART) is modelled by adding two stages to the basic four-stage model of HIV survival: stage 5 represents individuals currently on HAART, and stage 6 represents individuals who have discontinued HAART. Individuals are assumed to start treatment at the time of their first AIDSdefining illness, i.e. on progressing from HIV stage 3 to HIV stage 4 . For each of stages 1 to 4 , a record is kept of the proportion of individuals who have received voluntary counselling and testing (VCT) and know their HIV status. All individuals who are on HAART or who were previously on HAART are assumed to know their HIV status. This model of disease progression is represented in Figure 1.

The total time from HIV infection to death in adults has been found to depend on the age at HIV infection (Collaborative Group on AIDS Incubation and HIV Survival 2000). AIDS mortality rates and proportions of individuals in each of the six disease stages are therefore calculated at each integer duration of HIV infection for three infection ages: 19, 29 and 39. For other ages at infection, AIDS mortality rates and proportions in different stages, at integer durations of infection, are interpolated or extrapolated from those calculated at the three pivot ages. The mean time from HIV infection to death, in the absence of HAART, is assumed to be 12 years for individuals infected at age 19, 11 years for individuals infected at age 29 and 9.5 years for individuals infected at age 39 or older (median survival times are roughly half a year shorter in each case). These assumptions are set to be consistent with survival rates in the developed world, as local studies do not suggest that HIV survival in South Africa differs substantially from that in the developed world (Glynn et al. 2005; Maartens et al. 1997; Badri et al. 2004), and lower HIV survival assumptions tend to produce higher estimates of the number of deaths than have been observed in South Africa.

Estimates of the proportion of adult HIV survival time spent in each of WHO stages 1 to 4, in the absence of HAART, are derived from application of simple Markov models to survival data collected from a number of settings (Morgan et al. 2002a; Morgan et al. 2002b; Malamba et al. 1999; Deschamps et al. 2000; Longini et al. 1989; Davidse 2000). The estimated proportions, shown in Table 3, are used to estimate the mean time spent in each stage of disease, for each of the three pivot ages. The time spent in stage $t$ of disease is assumed to follow a Weibull distribution, parameterized in terms of a median $\left(m_{t}\right)$ and shape parameter $\left(\phi_{t}\right)$, both of which are related to the mean $\left(\mu_{t}\right)$ by the following formulae: 


$$
\begin{gathered}
\phi_{t}=\phi_{4}+b\left(\mu_{t}-\mu_{4}\right) \\
m_{t}=\frac{\mu_{t}(\ln 2)^{1 / \phi_{t}}}{\Gamma\left(1+1 / \phi_{t}\right)}
\end{gathered}
$$

As equation (5) shows, the means and shape parameters for the different stages are assumed to be linearly related. Parameter $\phi_{4}$ is set at 1 , and parameter $b$ is set at 0.35 , in order to replicate the 'shape' of the survivor functions observed in the developed world (Collaborative Group on AIDS Incubation and HIV Survival 2000).

Table 3: $\quad$ Stage-specific parameters

\begin{tabular}{lcccc}
\hline & $\begin{array}{c}\% \text { of total } \\
\text { survival time } \\
\text { spent in stage }\end{array}$ & $\begin{array}{c}\text { Relative } \\
\text { frequency } \\
\text { of sex }\end{array}$ & $\begin{array}{c}\text { Reduction in } \\
\text { frequency of } \\
\text { sex }\end{array}$ & $\begin{array}{c}\text { Reduction in \% } \\
\text { of sex acts } \\
\text { unprotected }\end{array}$ \\
\hline WHO stage 1 & $27.0 \%$ & 1 & $19 \%$ & $36 \%$ \\
WHO stage 2 & $19.8 \%$ & 1 & $19 \%$ & $36 \%$ \\
WHO stage 3 & $35.8 \%$ & 0.65 & $19 \%$ & $36 \%$ \\
$\begin{array}{l}\text { WHO stage 4 } \\
\text { Stage 5 (on } \\
\text { HAART) }\end{array}$ & $17.4 \%$ & 0.25 & $31 \%$ & $53 \%$ \\
$\begin{array}{c}\text { Stage 6 (off } \\
\text { HAART) }\end{array}$ & - & 0.8 & $31 \%$ & $53 \%$ \\
\hline
\end{tabular}

${ }^{*}$ Assuming HAART is not available.

As shown in Figure 1, individuals on HAART ultimately either discontinue treatment or die while on treatment. The probabilities of AIDS death and discontinuation of HAART in the first six months on HAART (0.0821 and 0.0914 respectively) are assumed to be particularly high. Thereafter, annual probabilities of AIDS death while on HAART and discontinuation of HAART (both 0.0584) are assumed to remain constant. After discontinuing HAART, individuals are assumed to experience the same AIDS mortality rates as untreated individuals in HIV stage 4. These assumptions result in a decline in AIDS mortality rates consistent with the 70 to $80 \%$ reductions in AIDS mortality rates observed after starting HAART in various studies (Palella et al. 1998; Murphy et al. 2001; Jordan et al. 2002). These and other studies (Badri et al. 2004) also suggest a 60 to $85 \%$ reduction in the incidence of opportunistic infections after starting HAART. It is therefore assumed that only $25 \%$ of individuals in stages 5 and 6 are classified as 'AIDS sick'. 
Figure 1: Model of HIV disease progression in adults, incorporating the effects of HAART and knowledge of HIV status

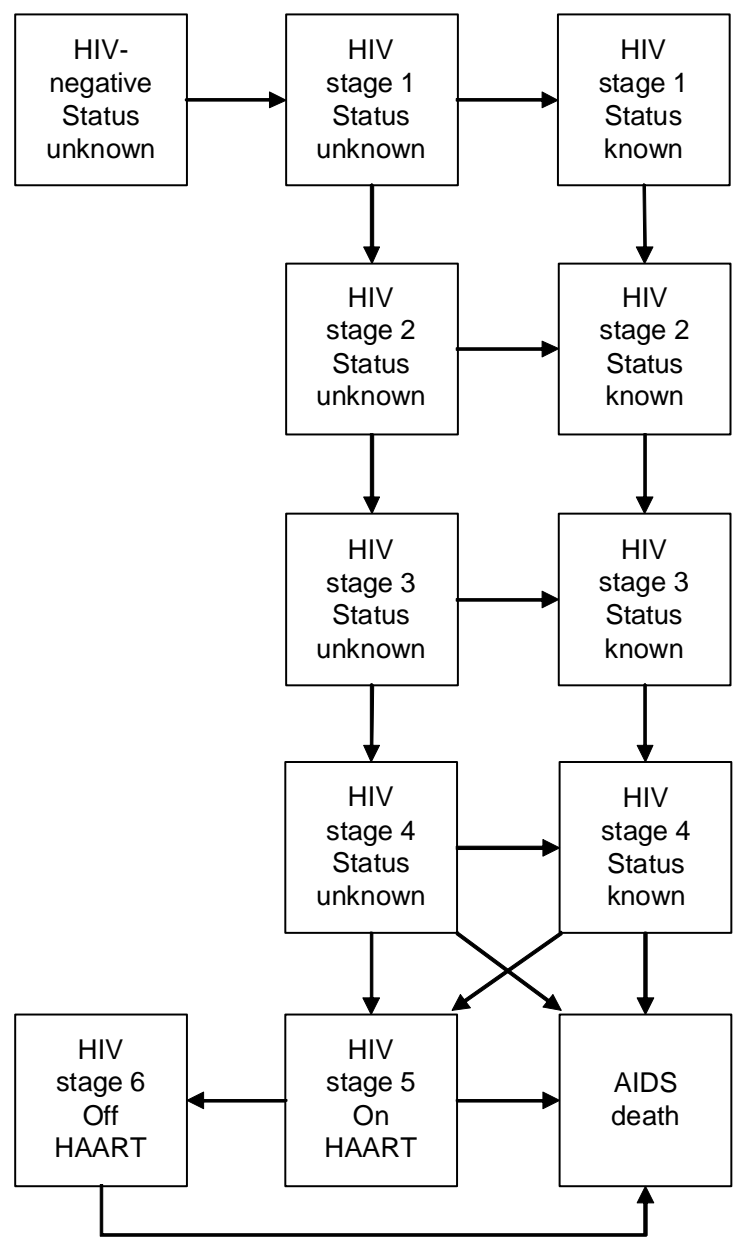


As individuals enter the later stages of HIV disease, coital frequencies decrease due to increased morbidity (Ross et al. 2004; Terceira et al. 2003; Hankins, Tran and Lapointe 1998; Wilson et al. 2004). The frequency of sex in stage $t$, expressed as a multiple of the frequency of sex in stages 1 and 2 (the asymptomatic stages), is set to vary according to the severity of symptoms in stage $t$. The assumed values of these multiples are shown in Table 3. Further changes in sexual behaviour are assumed to occur when HIV-infected individuals learn their HIV status through VCT programmes. Table 3 also shows the assumed reductions in the frequency of sex and in the proportion of coital acts that are unprotected in HIV-positive individuals who know their HIV status, based on studies by the VCT Efficacy Study Group (2000) and De Vincenzi (1994).

\subsection{Modelling of sexual transmission}

The parameter $T_{t i j}(y)$ is defined as the probability that an HIV-positive $y$-year old woman, in stage $t$ of disease and in risk group $j$, transmits the virus to a partner in risk group $i$ in a single act of sex. The parameter is calculated using the formula

$$
T_{t i j}(y)=r_{i j} \cdot I_{t}\left(1-\left[1-\left(1-c_{j}(y)\right) R_{t}\right] e\right)
$$

where

- $r_{i j}$ is the average probability of transmission from an HIV-positive female in risk group $j$ to an HIV-negative male in risk group $i$, in a single act of unprotected sex;

- $I_{t}$ is the factor by which $r_{i j}$ is multiplied if the HIV-positive female is in stage $t$ of disease;

- $c_{j}(y)$ is the probability that a sero-discordant couple use a condom when the index partner is aged $y$ and in risk group $j$;

- $R_{t}$ is the factor by which the proportion of sex acts that are unprotected is multiplied in stage $t$ of disease (taking into account the effect of knowledge of HIV status); and

- $e$ is the probability that a condom is effective in preventing HIV transmission in a single act of sex (assumed to be 0.95).

A similar formula is used to define the probability of male-to-female transmission, with male-specific parameters $T_{t i j}^{*}(y), r_{i j}^{*}$ and $R_{t}^{*}$ replacing $T_{t i j}(y), r_{i j}$ and $R_{t}$ respectively. 
On the basis of studies of HIV transmission in stable sero-discordant partnerships (Downs and De Vincenzi 1996; Peterman et al. 1988; Wiley, Herschkorn and Padian 1989; Gray et al. 2001), the parameters $r_{33}$ and $r_{33}^{*}$ are set at 0.001 and 0.002 respectively (these parameters apply when both partners are in the RSK group). To reflect the effect of STDs on HIV transmission, it is assumed that transmission probabilities are higher when both partners are either in the PRO or STD group $\left(r_{11}=r_{12}=r_{21}=r_{22}=0.005\right.$ and $\left.r_{11}^{*}=r_{12}^{*}=r_{21}^{*}=r_{22}^{*}=0.007\right)$, or one partner is in the STD group and the other in the RSK group $\left(r_{23}=r_{32}=0.003\right.$ and $\left.r_{23}^{*}=r_{32}^{*}=0.0045\right)$.

HIV transmission probabilities are assumed to vary according to the stage of disease, with transmission being most efficient in those stages with the highest average levels of viral load. Based on estimates of change in viral load over the course of HIV infection (Kassa et al. 1999; Hubert et al. 2000), and an assumed 3-fold increase in HIV transmissibility per log increase in viral load (Quinn et al. 2000; Fideli et al. 2001), the values of $I_{1}, I_{2}, I_{3}$ and $I_{4}$ are set at $0.5,0.4$., 1.5 and 2.9 respectively. It is assumed that HIV viral load while on antiretroviral treatment is 1.76 log below that in stage 4 (Jordan et al. 2002), and the value of $I_{5}$ has therefore been set at $0.4\left(=2.9 \times 3^{-1.76}\right)$. After discontinuation of treatment, levels of infectiousness are assumed to return to those in untreated AIDS (i.e. $I_{6}=I_{4}$ ).

Probabilities of HIV infection are calculated at annual intervals. The probability that a female aged $x$, in risk group $i$, becomes infected in a given year is calculated as

$$
1-\left\{1-a(x) \sum_{j=1}^{4} w_{i j} \sum_{y=14}^{59} f(y \mid x) \sum_{t=1}^{6} p_{t j}(y)\left[1-\left(1-T_{t i j}^{*}(y)\right)^{n_{i j} s_{y}^{*} D_{t}}\right]\right\}^{P_{i} S_{x}}
$$

where

- $a(x)$ is the factor by which the per-partnership transmission probability is multiplied in women aged $x$;

- $w_{i j}$ is the proportion of male partners who are in risk group $j$ (Table 1);

- $p_{t j}(y)$ is the proportion of male partners (aged $y$ and in risk group $j$ ) who are HIVpositive and in stage $t$ of disease;

- $n_{i j}$ is the number of coital acts per partnership between a female in risk group $i$ and a male in risk group $j$ (Table 1);

- $D_{t}$ is the factor by which the coital frequency is multiplied in stage $t$ of disease (taking into account the effect of disease symptoms and knowledge of HIV status);

- $P_{i}$ is the average annual number of partners for a woman in group $i$ (Table 1). 
A similar formula for the annual infection probability is used for males, with female-specific parameters being replaced by male-specific parameters.

Studies suggest that transmission probabilities are particularly high in women under the age of 25 (Carpenter et al. 1999), possibly as a result of the high prevalence of cervical ectopy in young women (Plourde et al. 1994). The factor $a(x)$ is therefore set to 1 for all women over the age of 25 , and is increased at younger ages according to the formula

$$
a(x)= \begin{cases}1.1^{5} \times 1.15^{20-x} & 14 \leq x<20 \\ 1.1^{25-x} & 20 \leq x<25\end{cases}
$$

The factor $a(x)$ is omitted from the calculation of female-to-male transmission.

\subsection{Modelling vertical transmission and paediatric HIV survival}

Two distinct patterns of mother-to-child transmission of HIV are modelled: intrauterine/intrapartum transmission (transmission before or during birth) and transmission through breast milk. It is assumed that in the absence of intervention, 20\% of HIV-positive mothers would transmit the virus to their child before or during birth (Nduati et al. 2000; Dabis et al. 1999; Coutsoudis et al. 1999), and 16\% of the remainder would subsequently transmit the virus to their child as a result of breastfeeding (Miotti et al. 1999; Nduati et al. 2000). The age at infection through breast milk is assumed to be uniformly distributed over the first year of life, with equal numbers of children infected through breast milk in the first six months of life and in the second six months.

The modelling of paediatric HIV survival is similar to that of adult HIV survival, with two important differences. Firstly, the four-stage WHO clinical staging system for adults is replaced with a simple two-stage system (pre-AIDS and AIDS). Secondly, survival assumptions differ for children who are infected before or at birth and children infected through breast milk, with children infected intrauterine/intrapartum being assumed to experience more rapid disease progression. As in adults, the time spent in each of the non-antiretroviral stages is assumed to follow a Weibull distribution, and antiretroviral treatment is assumed to start at the time that children experience their first AIDS-defining illness. In common with the adult survival model, the shape parameter for the Weibull distribution is set at 1 for the AIDS stage, and the distribution of survival times in the 'off treatment' stage is assumed to be the same as that for the untreated AIDS stage. 
Assumptions about the time spent in each stage were set so that the aggregate paediatric HIV survivor function was roughly consistent with the 'upper limit' on the survivor function estimated by Marston et al (2005). (The upper limit was chosen instead of the best fit to the data, to be consistent with the high assumed rates of adult HIV survival in South Africa, relative to the rates observed in other developing countries.) This survivor function is a double Weibull distribution, with 'fast progression' and 'slow progression' components (assumed to be appropriate to intrauterine/intrapartum infections and breast milk infections respectively). For children infected before or during birth, the time spent in the pre-AIDS stage follows a Weibull distribution with median 0.5 years and shape parameter 0.7 , and the median time in the AIDS stage is 0.3 years (Hussey et al. 1998). For children infected by breast milk, the pre-AIDS survivor function is Weibull with median 7.8 years and shape parameter 5.5, and the median survival time in the AIDS stage is 0.93 years.

\subsection{Modelling of prevention and treatment programmes}

Five intervention programmes are modelled: VCT, prevention of mother-to-child transmission (PMTCT), HAART, improved STD treatment, and social marketing. Assumptions are made about the year in which each programme is introduced and the proportion of the population that has access to the treatment or prevention service in each subsequent year (Table 4). These assumptions reflect the actual experience in South Africa to date, based on published and unpublished data discussed below.

VCT is assumed to result in a reduction in unprotected sex in individuals who test HIV-positive, as described previously. It is assumed that if VCT was readily accessible and well-publicized, 6\% of adults at risk of infection would seek VCT per annum (Scott et al. 2005; Fylkesnes et al. 1999). It is further assumed that $80 \%$ of women receiving antenatal care agree to VCT if the service is offered to them as part of a PMTCT programme (Abdullah et al. 2001). Adults also automatically receive VCT before starting HAART if they are not already aware of their HIV status. The proportions in the VCT row of Table 4 are the proportions of adults with access to VCT and awareness of the VCT programmes on offer, based on estimates of VCT access in the South African public sector in 2002 (Ramkissoon et al. 2004).

The proportions in the PMTCT row in Table 4 are the proportions of pregnant women assumed to be offered PMTCT in each year, based on early reports (Ramkissoon et al. 2004; McCoy et al. 2002). It is assumed that if women agree to VCT, all of those who test positive receive short-course antiretroviral treatment to prevent perinatal transmission of HIV. The regimen currently offered is the HIVNET 012 regimen, which is assumed to result in a $47 \%$ reduction in intrauterine/intrapartum 
transmission (Guay et al. 1999). It is also assumed that women participating in the PMTCT programme have a 50\% lower risk of transmitting the virus to their child through breast milk, as a result of the promotion of formula milk and exclusive breastfeeding to these mothers.

\section{Table 4: $\quad$ Rates of intervention phase-in}

\begin{tabular}{lcrrrrrrrrrr}
\hline Intervention & $\begin{array}{l}\text { Year } \\
\text { intro- } \\
\text { duced }\end{array}$ & $\begin{array}{r}\text { Rates of phase-in } \\
\text { dur 1 }\end{array}$ & Yr 2 & Yr3 & Yr 4 & Yr 5 & Yr6 & Yr7 & Yr 8 & Yr 9 & Yr 10* \\
\hline VCT & 1995 & $8 \%$ & $17 \%$ & $25 \%$ & $33 \%$ & $42 \%$ & $50 \%$ & $58 \%$ & $67 \%$ & $75 \%$ & $83 \%$ \\
PMTCT & 2001 & $10 \%$ & $40 \%$ & $60 \%$ & $80 \%$ & $90 \%$ & $90 \%$ & $90 \%$ & $90 \%$ & $90 \%$ & $90 \%$ \\
HAART & & & & & & & & & & & \\
'Constrained' & 2000 & $2 \%$ & $4 \%$ & $6 \%$ & $8 \%$ & $17 \%$ & $25 \%$ & $34 \%$ & $42 \%$ & $50 \%$ & $50 \%$ \\
'Optimistic' & 2000 & $2 \%$ & $4 \%$ & $6 \%$ & $8 \%$ & $25 \%$ & $41 \%$ & $58 \%$ & $74 \%$ & $90 \%$ & $90 \%$ \\
STD treatment & 1994 & $10 \%$ & $30 \%$ & $50 \%$ & $80 \%$ & $90 \%$ & $95 \%$ & $95 \%$ & $95 \%$ & $95 \%$ & $95 \%$ \\
Social marketing & 1994 & $3 \%$ & $7 \%$ & $12 \%$ & $20 \%$ & $33 \%$ & $50 \%$ & $66 \%$ & $80 \%$ & $90 \%$ & $95 \%$ \\
\hline
\end{tabular}

* Rates of phase-in achieved by the $10^{\text {th }}$ year are assumed to be maintained at the same level in all subsequent years.

HAART is assumed to have benefits both in terms of improved survival and reduced HIV infectiousness, as previously described. The proportions in the HAART rows in Table 4 are the proportions of new AIDS cases starting antiretroviral treatment in each year. The assumptions prior to 2004 are based on historical estimates of numbers treated, mostly in the private health sector (McLeod, Achmat and Stein 2003). Much uncertainty exists, however, regarding the likely future pace and extent of antiretroviral treatment rollout. Two treatment scenarios are therefore considered: a 'constrained' scenario in which ultimately only 50\% of new AIDS cases are able to access treatment, and an 'optimistic' scenario in which the percentage of new AIDS cases starting HAART rises to $90 \%$.

Improved STD treatment in South Africa is mostly the result of syndromic management protocols in public STD clinics. This began in 1994, and by 1999 virtually all public STD clinics were following syndromic management guidelines (Dr D. Coetzee, University of Cape Town, personal communication). This improvement is assumed to result in a reduction in average HIV transmission probabilities: by $15 \%$ when both partners are in either the PRO or STD group, by $10 \%$ when one partner is in the STD group and the other in the RSK group, and by 5\% when both partners are in the RSK group. The reductions assumed are thus commensurate with the STD prevalence rates in the different risk groups. The reductions assumed are also conservative, as there is little evidence of similar improvements in STD treatment in the private health sector, which treats roughly half of all STD cases (Schneider et al. 2001). 
Social marketing is assumed to have resulted in increased condom usage, as previously described. Based on the significant improvements in condom usage that have been observed, it is assumed that condom usage is three times more common in individuals with good knowledge of HIV/AIDS and easy access to condoms than in those who have little knowledge of the disease or poor access to condoms. The proportions in the 'Social marketing' row of Table 4 are the proportions of sexually active adults who are exposed to social marketing on a regular basis in each year, who are assumed to have good knowledge of HIV/AIDS and easy access to condoms. These were set to be such that the average rates of condom usage in 1998 and 2002 were roughly consistent with those estimated in surveys (Department of Health 1999; Human Sciences Research Council 2002). The proportions are also consistent with the rise in numbers of male condoms distributed since 1994 (Myer 2005).

In the analysis that follows, four intervention scenarios are considered:

- 'no intervention' scenario: none of the prevention and treatment programmes described above are introduced at any time,

- 'prevention only' scenario: assumes the same rates of intervention phase-in as in Table 4, except that there is no HAART rollout,

- 'constrained' scenario: prevention programmes are coupled with a constrained HAART rollout, and

- 'optimistic' scenario: prevention programmes are coupled with an optimistic HAART rollout.

The 'constrained' scenario corresponds to the default scenario in the publicly available ASSA2002 model.

\subsection{Calibration}

Model estimates of numbers of adult deaths, by sex and five-year age band, are compared with empirically derived estimates of numbers of deaths for each year from 1996 to 2002 (Dorrington, Moultrie and Timæus 2004). (Vital registration of adult deaths is estimated to be about $85 \%$ complete for the period 1996 to 2001, and thus the estimated numbers of deaths, corrected for incompleteness, can be considered to be fairly reliable.) Model estimates of HIV prevalence in pregnant women using public antenatal clinics, by five-year age band, are compared with those observed in the nationally representative antenatal clinic surveys, for each year from 1991 to 2002. In order to produce model estimates of prevalence in pregnant women attending public clinics, it is necessary to allow for the effect of HIV on fertility, correlation between pregnancy and HIV risk behaviour at young ages, and socioeconomic bias in the antenatal sample. 
To obtain the age-specific fertility rate of an HIV-positive woman aged $x$, who has been infected for $d$ years, the fertility rate in HIV-negative women of the same age is multiplied by a factor proportional to

$$
A_{x}\left(1-B_{x}\right)^{d}
$$

where $B_{x}$ is the percentage by which fertility reduces per year of HIV infection, and $A_{x}$ is a factor introduced to allow for the positive correlation between childbearing and risk of HIV infection at young ages. These parameters were set to be such that the ratios of antenatal prevalence to general female prevalence in each five-year age band were approximately consistent with those ratios estimated from southern African surveys (Gregson et al. 2002; Human Sciences Research Council 2002). Parameter $B_{x}$ was set at $4 \%$ for all $x$. $A_{14}$ was set at 1.5 , with a $20 \%$ reduction in the difference between $A_{x}$ and 1 for each year of increase in age.

The model estimates of prevalence in pregnant females were multiplied by 'antenatal adjustment factors' to allow for the under-representation of women of higher socio-economic status in the public antenatal clinic survey. These factors were derived based on health-seeking behaviour data by age and race from the 1998 DHS, together with unpublished estimates of HIV prevalence by age, race and medical scheme membership, derived by the authors. The antenatal adjustment factors for the different five-year age bands vary between 1.08 and 1.18 .

\section{Results}

Model estimates of HIV prevalence in antenatal clinics and numbers of deaths in the constrained scenario are compared with empirical estimates in Figures 2 and 3 respectively. The correspondence between observed and modelled antenatal prevalence in recent years is close, with the model estimating a prevalence of $25.6 \%$ in pregnant women attending public clinics in 2002, just less than the prevalence of $26.5 \%$ observed in the survey. The modelled prevalence in the earlier years is deliberately set below the reported antenatal prevalence, to allow for the bias towards urban clinics in the early antenatal surveys, which was only corrected when new survey protocols were introduced between 1997 and 2000 (Department of Health 2001). Comparison of prevalence by age group shows a levelling in the observed 15-24 prevalence in recent years and a continued rise in 25-29 prevalence, neither of which is closely reproduced by the model (results not shown). 


\section{Figure 2: $\quad$ Observed and modelled HIV prevalence in women attending public antenatal clinics}

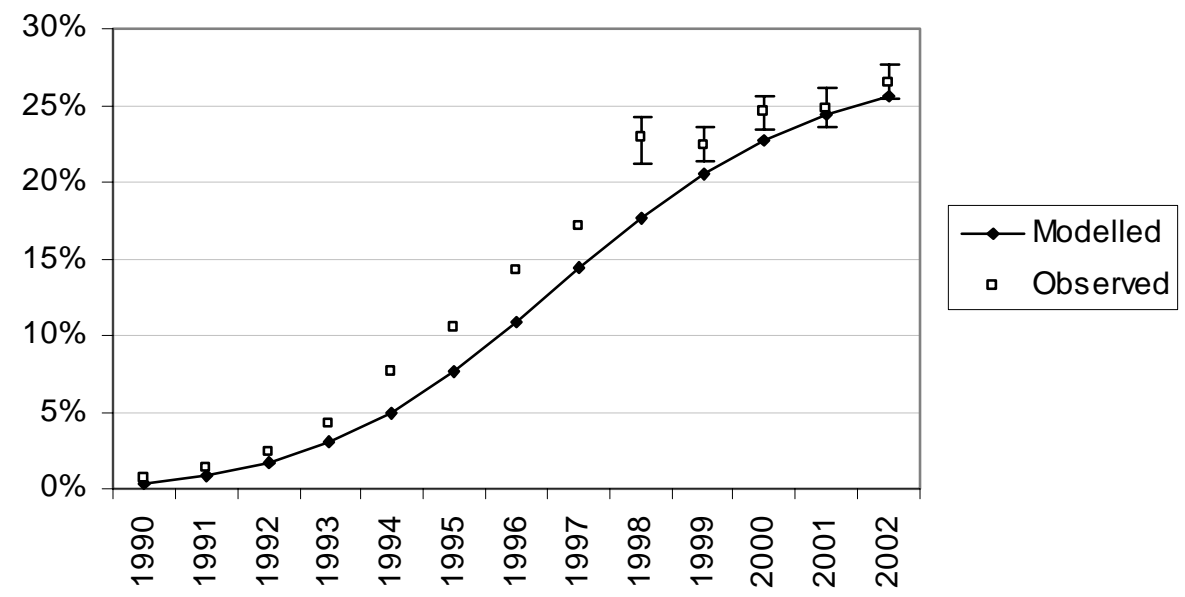

95\% confidence intervals are shown for antenatal survey estimates after 1997.

Estimates of numbers of deaths between the ages of 15 and 59 are close to those derived empirically, although the model appears to over-estimate the mortality to some extent in males between the ages of 35 and 45 and in females between the ages of 25 and 45 .

The results of the ASSA2002 model for the four scenarios considered are shown in Figure 4. In the absence of interventions, it is estimated that the HIV incidence rate would have risen to its highest level in 1998 and thereafter declined (Figure 4a), due to decreasing numbers of HIV-susceptible individuals in the high-risk groups. Prevention programmes have led to some reduction in HIV incidence, but HIV incidence remains high in all three intervention scenarios. The introduction of HAART is expected to have little impact on HIV incidence, with the difference in incidence in the 'prevention only' and 'optimistic' scenarios lying below $0.1 \%$ in all years. HAART is, however, expected to have a significant impact on HIV prevalence, due to the improved survival prospects of infected individuals. The effect of prevention programmes is to reduce HIV prevalence in 2005 by roughly $2 \%$ (Figure 4b). By 2020, the prevalence expected if prevention is not coupled with HAART is well below that which would be expected if prevention was coupled with a high level of HAART rollout. 
Figure 3: $\quad$ Modelled and empirically derived estimates of male and female deaths in 2002/2003

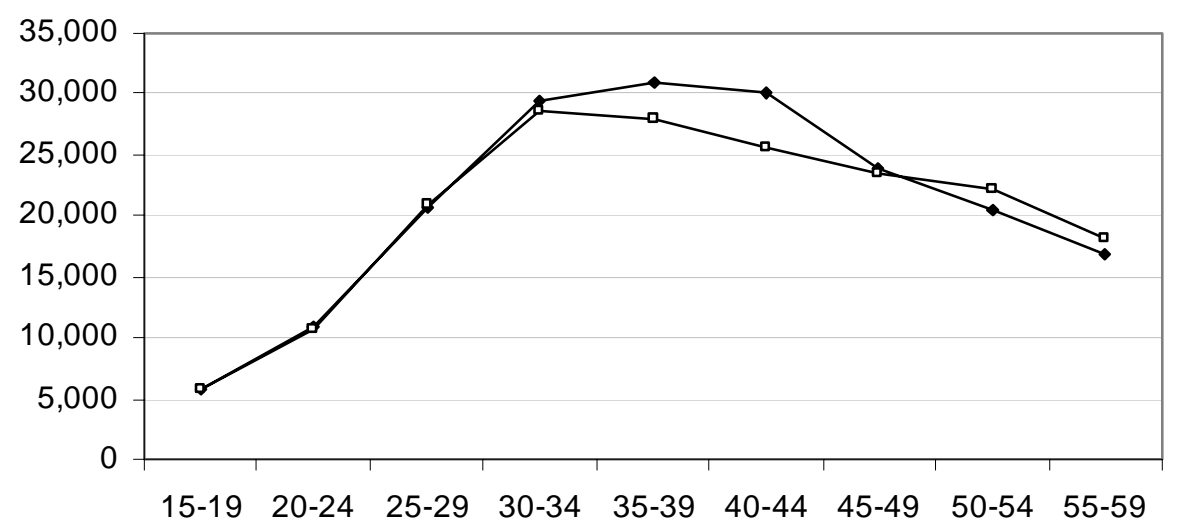

(a) Male deaths

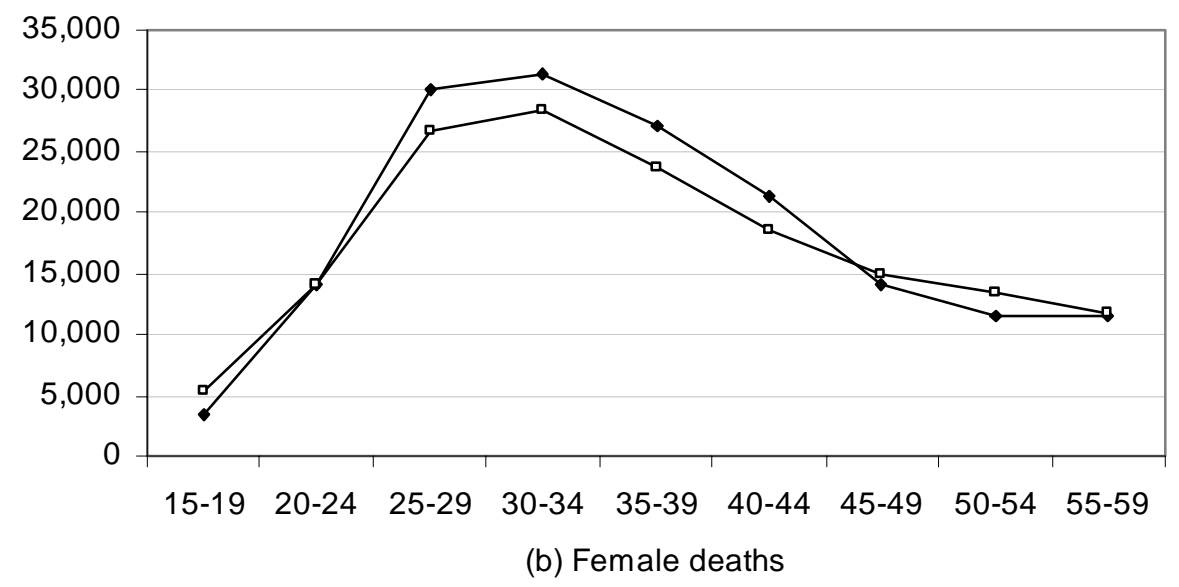

Model estimates (solid diamonds) and empirically derived estimates (open squares) are shown for each five-year age band in the 15 to 59 age group. 
Figure $4 \mathrm{c}$ shows the increase in the crude mortality rate due to AIDS, or the percentage of the population dying due to AIDS in each year. By 2010, there is significant divergence between the four scenarios, with the increase in the crude mortality rate due to AIDS being more than twice as high in the 'no intervention' scenario as in the 'optimistic' scenario. Over the longer term, however, the differences between the three intervention scenarios diminish, due to the assumed limited duration of the HAART survival benefit. A similar trend is observed in respect of the life expectancy at birth (Figure 4d). In 2010, life expectancy is projected to be almost seven years higher in the 'optimistic' scenario than in the 'prevention only' scenario. By 2020, however, the life expectancy in the 'optimistic' scenario is projected to exceed that in the 'prevention only' scenario by only three years.

The child mortality rate (number of deaths per 1000 births in the first five years of life) is also significantly affected by HIV/AIDS prevention and treatment. In the absence of intervention, this rate would be expected to rise by roughly 30 per 1000 from 1990 to 2010 (Figure 4e). As a result of prevention programmes (mostly PMTCT), there is a reduction of almost 25 deaths per 1000 births in 2010 and subsequent years, relative to the 'no intervention' scenario. With the inclusion of HAART in the intervention package, even greater reductions in child mortality would be expected.

Coinciding with the rise in AIDS mortality are rapid increases in the percentage of children whose mothers have died (maternal orphans). It is expected that in the absence of interventions, the percentage of children under the age of 18 whose mothers have died would increase more than five-fold between 1990 and 2015 (Figure 4f). Prevention programmes have little impact on rates of orphanhood, as reductions in orphanhood due to reduced adult mortality are largely offset by increases in orphanhood due to lower rates of mother-to-child transmission. However, the introduction of HAART has a significant impact on orphan numbers. The proportion of children aged less than 18 who are maternally orphaned in 2015 would, in the 'optimistic' scenario, be only two thirds of that in the 'no intervention' scenario.

Figure 5 shows trends in the age profile of newly infected individuals and trends in the morbidity profile of the infected adult population, for the 'no intervention' and 'optimistic' scenarios. In 1995, less than one in five HIV infections are estimated to have been acquired by infants, from their infected mothers, or by teenagers, through sexual exposure. As the epidemic progresses, the proportion of new infections occurring below the age of 20 increases, due to 'saturation' of the epidemic at older ages. In the 'no intervention' scenario, it is estimated that almost half of new HIV infections occur below the age of 20 by 2020 (Figure 5a). This proportion is reduced in the 'optimistic' scenario (Figure 5b), partly because of reduced mother-to-child transmission, and partly because reductions in unprotected sex lead to longer intervals between sexual debut and HIV infection. 


\section{Figure 4: $\quad$ HIV incidence, HIV prevalence and impact of HIV/AIDS} on demographic indicators

(a) HIV incidence

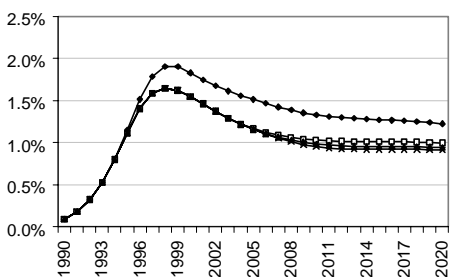

(c) Increase in crude mortality rate

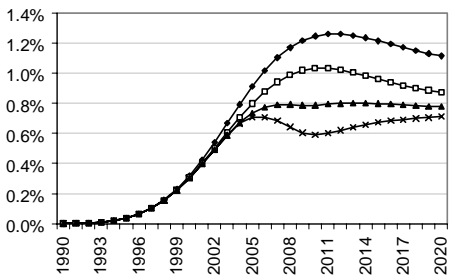

(e) Child mortality rate

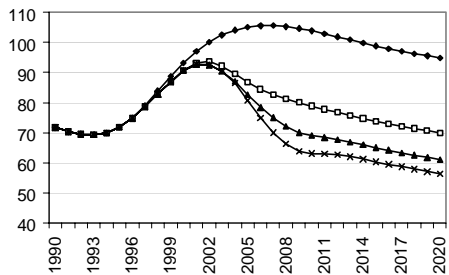

(b) HIV prevalence

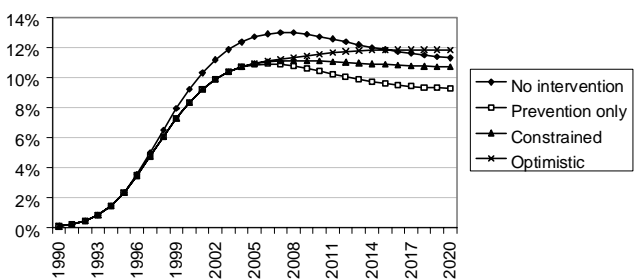

(d) Life expectancy at birth

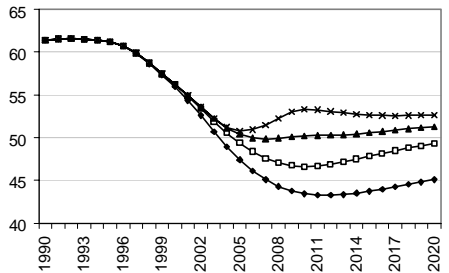

(f) \% of children maternally orphaned *

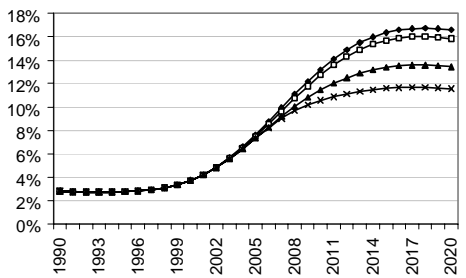

$\rightarrow$ No intervention $\rightarrow-$ Prevention only $\rightarrow$ Constrained $\rightarrow$ Optimistic

\footnotetext{
* The percentage of children maternally orphaned is defined here as the proportion of children under the age of 18 who have lost either a mother or both parents.
}

The morbidity profile of the HIV-infected adult population also changes over the course of the epidemic. In 1995, almost 90\% of all HIV-positive adults were in WHO stages 1 and 2, the asymptomatic stages of disease. This asymptomatic proportion is expected to decline to roughly a half in the 'no intervention' scenario and to a third in the 'optimistic' scenario, by 2015 (Figures 5c and 5d). The proportion which is 
symptomatic and untreated (stages 3 and 4) in 2015 also differs substantially between the 'no intervention' scenario and the 'optimistic' scenario.

The morbidity profile in 2015 can be further analysed by age (Figure 6). Although Figure $2 \mathrm{~b}$ shows similar aggregate levels of HIV prevalence in 2015 in the 'no intervention' and 'optimistic' scenarios, there are significant differences between the two scenarios in terms of the age profile of the infected population. Below the age of 30, HIV prevalence is higher in the 'no intervention' scenario than in the 'optimistic' scenario, due to the impact of prevention programmes in the latter. Over the age of 30, however, HIV prevalence is higher in the 'optimistic' scenario, due partly to the greater survival under HAART and partly to the shifting of HIV incidence to the older ages. Most infections below the age of 25 are asymptomatic (WHO stages 1 and 2), as they are recently acquired. The need for HAART is likely to be greatest between the ages of 30 and 50, at over $10 \%$ of the population in this age band.

Figure 5: $\quad$ Trends in the age profile of new HIV infections and the morbidity profile of adult HIV infections, for the 'no intervention' and 'optimistic' scenarios

(a) Age profile, 'no intervention' scenario

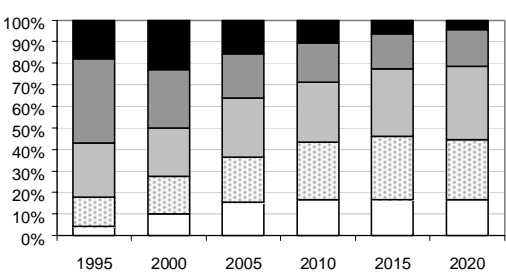

(c) Morbidity profile, 'no intervention' scenario

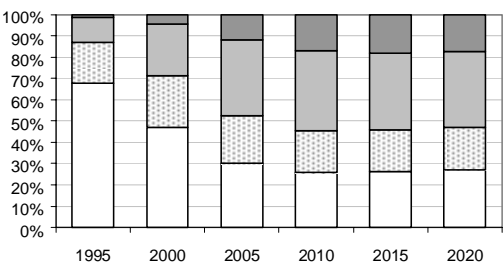

(b) Age profile, 'optimistic' scenario

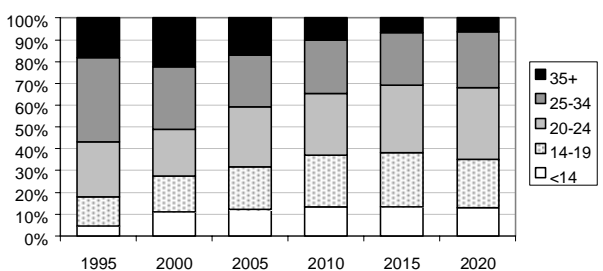

(d) Morbidity profile, 'optimistic' scenario

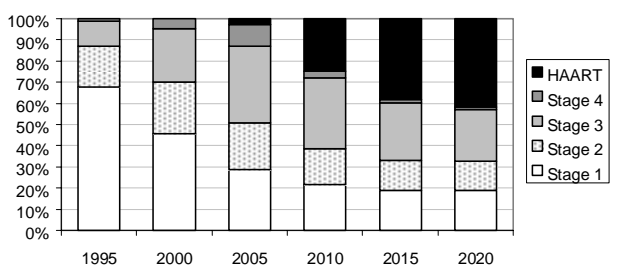

Adult infections are grouped according to WHO clinical stage, with 'HAART' representing individuals who either are on treatment or have discontinued treatment. 
Figure 6: $\quad$ Percentage of population infected by age, split by disease stage, in 2015, for the 'no intervention' and 'optimistic' scenarios

(a) Morbidity prof ile, 'no intervention' scenario

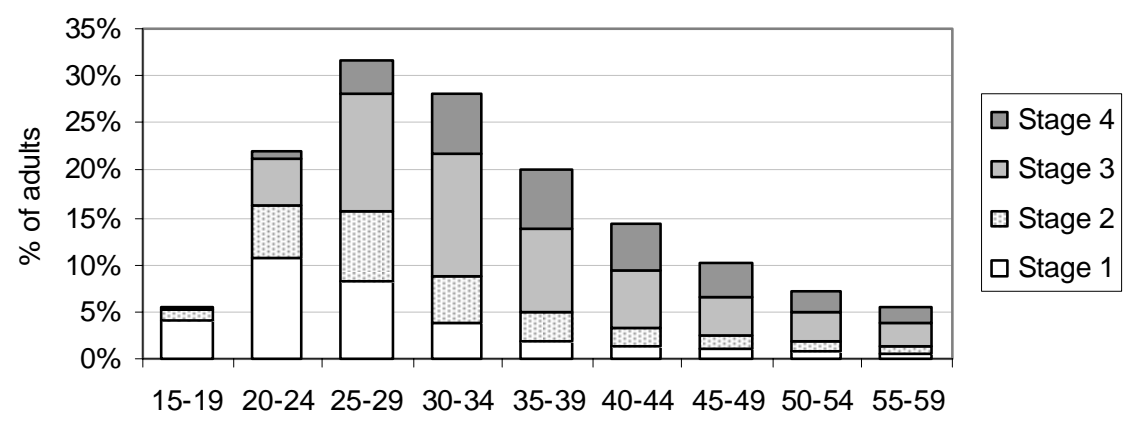

(b) Morbidity profile, 'optimistic' scenario

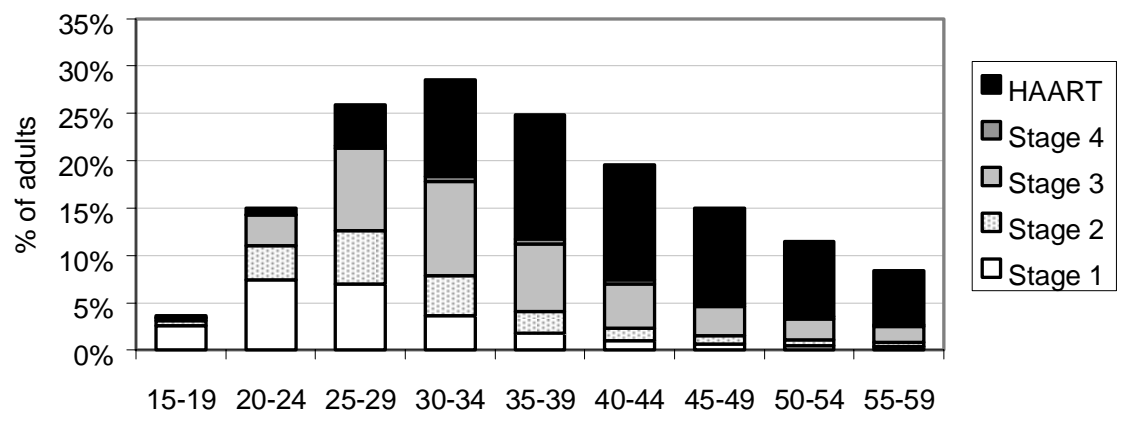

Adult infections are grouped according to WHO clinical stage, with 'HAART' representing individuals who either are on treatment or have discontinued treatment.

\section{Discussion}

The ASSA2002 model confirms that HIV/AIDS is having a significant demographic impact in South Africa. The ASSA2002 model also demonstrates that the prevention and treatment programmes that have been and are being introduced can significantly 
modify this demographic impact. Even when interventions do not substantially alter HIV prevalence, they can result in a shift of HIV incidence from younger to older ages, as well as an extension of HIV survival, both of which reduce the years of life lost due to HIV/AIDS.

HIV prevention programmes appear to have had a modest impact on HIV incidence, with much of the reduction in HIV incidence taking place in the absence of prevention programmes. HAART is expected to have little impact on HIV incidence, but further sensitivity testing is necessary to check the robustness of this conclusion, particularly as the model does not currently assume any change in utilization of VCT or any change in sexual behaviour in HIV-negative individuals after HAART becomes available. Other models suggest that HAART will lead to a reduction in HIV prevalence (Nagelkerke et al. 2002; Boily et al. 2004; Gray et al. 2003), reflecting a significant positive effect of HAART on HIV incidence. The ASSA2002 model predicts a less significant preventative benefit from HAART because it assumes a slower phase-in of the intervention and because it assumes HAART is initiated in later stages of HIV disease.

South Africa would still be experiencing significant declines in life expectancy had interventions not been introduced. Prevention programmes have not had significant effects on mortality in the short term, though PMTCT is estimated to have contributed significantly to declines in the child mortality rate. More immediate reductions in mortality are observed when HAART is introduced. However, as other models have shown (Salomon et al. 2005), the difference in mortality rates between 'high HAART coverage' and 'low HAART coverage' scenarios diminishes over the longer term, due to the limited survival benefit from HAART. HAART has a more sustained benefit in terms of levels of orphanhood, as HAART defers mortality of parents to those ages at which their children have ceased to be dependent on them.

The ASSA2002 model is unique in modelling the profile of the HIV-positive population by WHO clinical stage, and this model output has proved useful in assessing the burden of disease due to HIV/AIDS (Bradshaw et al. 2003) as well as the costs of treatment and care for HIV/AIDS (Geffen, Nattrass and Raubenheimer 2003). Although HIV prevalence rates and AIDS mortality rates appear to be levelling off in the 'constrained' scenario, an increasingly high proportion of infected individuals are either symptomatic (WHO stage 3 or 4 ) or on HAART. The need for treatment is greatest over the age of 25 , while an increasingly high proportion of new infections are occurring below the age of 25 . This suggests that prevention programmes need to be tailored to the youth, while treatment literacy and treatment screening would be particularly appropriate in older age groups.

A strength of the ASSA2002 model is that it is calibrated to both HIV prevalence data and vital registration data, and produces results roughly consistent with both. 
However, the consistency is poor in some age groups. Extensive uncertainty analysis of the ASSA2002 model has failed to identify parameter combinations that give significantly improved fits to the age pattern of HIV prevalence and mortality, although correspondence with observed HIV prevalence in the 15 to 19 age group improves when it is assumed that social marketing programmes lead to reductions in rates of partner change (Johnson, Dorrington and Matthews 2006). It is therefore possible that the effects of social marketing are not limited to condom usage, as assumed here. The correspondence with the observed 15 to 24 prevalence might also be improved if the model were adapted to allow for greater effectiveness of STD treatment at young ages, when curable STDs are relatively more prevalent (Buvé et al. 2001) and incurable STDs relatively less prevalent (Smith and Robinson 2002). Correspondence with reported male deaths in the 35 to 44 age group might also be improved if allowance were made for higher rates of antiretroviral access in this group, linked to higher rates of medical scheme membership (Department of Health 1999). Calibration of AIDS models to data in five-year age bands can therefore yield important hypotheses about the effects of interventions and how they differ in relation to age and sex.

In the ASSA2002 model, approximate consistency between model outputs and reported levels of HIV prevalence and mortality is achieved mainly through changes to assumed proportions of the sexually active population in the four risk groups and changes to average annual numbers of partners in these risk groups. However, no reliable empirical data exist that can be used to verify these sexual behaviour assumptions. There is thus considerable uncertainty regarding sexual behaviour parameters, in addition to the general uncertainty regarding other model parameters. A Bayesian analysis of South African HIV prevalence and vital registration data, based on the ASSA2002 model, has shown that a wide range of sexual behaviour assumptions can produce model outputs consistent with these HIV prevalence and vital registration data (Johnson, Dorrington and Matthews 2006). The Bayesian analysis also demonstrated that the model outputs were broadly consistent with male and female HIV prevalence data and mortality data, in spite of the proportions of the population in the risk groups being set at the same level for males and females.

A limitation of the model is that HIV transmission probabilities are calculated on an annual basis. This makes it impractical to allow for transmission dynamics that operate over short time periods. For example, the period of high HIV viraemia around seroconversion lasts for only a few months, but is potentially very significant in the spread of HIV (Pilcher et al. 2004). STDs are also often only of short duration, but play an important role in increasing HIV susceptibility and HIV infectiousness while present (Røttingen, Cameron and Garnett 2001). The modelling of the effect of improved STD treatment in ASSA2002 is therefore of necessity simplistic, and models with shorter 
time steps are needed to simulate the interactions between HIV and other STDs more accurately.

Many uncertainties also apply in the modelling of other interventions. For example, the effectiveness of PMTCT programmes may well improve in future if zidovudine is used increasingly in combination with nevirapine, as is already happening in parts of the country (Eley 2005). Efficacy of HAART may also differ from that assumed here, as the evidence used in setting the HAART assumptions is drawn mostly from studies with short follow-up. It is also possible that utilization of counselling and testing services may increase beyond the levels assumed here, particularly with routine testing and 'opt-out' testing programmes being promoted increasingly in Africa (De Cock, Bunnell and Mermin 2006; Manzi et al. 2005). The ASSA2002 model allows for utilization of VCT through PMTCT and HAART programmes, but it is debatable whether this VCT and other 'opt-out' testing programmes would be as effective in changing behaviour in tested individuals as VCT initiated independently, by individuals concerned about their risk of HIV infection. Assumptions about VCT access and efficacy may therefore need to be revised in future.

The ASSA2002 model is an example of how the effects of HIV/AIDS and HIV/AIDS interventions can be incorporated into a cohort component projection model. The model demonstrates that the age profile of new HIV infections changes over the course of the epidemic, and changes in response to prevention and treatment programmes. This suggests that the approach of deriving adjustments to a cohort component projection model from an independent HIV/AIDS model is problematic if it is assumed that the age profile of HIV cases is fixed, as Stover (2004) notes. The ASSA2002 model also demonstrates that there is significant age variation in HIV/AIDS prevalence, morbidity and mortality. HIV/AIDS models which are based on very broad age divisions may therefore be difficult to validate reliably against prevalence and vital registration data, if the age distribution of these data differs from that of the population modelled. There is thus a strong case for greater integration of demographic modelling and disease modelling in the simulation of generalized HIV/AIDS epidemics.

\section{Acknowledgements}

This paper is based on a paper presented at the International Union for the Scientific Study of Population XXV International Population Conference (Tours, France, July 1823 2005). We would like to thank the discussant, members of the audience and reviewers for their comments, which helped to improve the paper. 


\section{References}

Abdullah M., Young T., Bitalo L., et al. (2001). Public health lessons from a pilot programme to reduce mother-to-child transmission of HIV-1 in Khayelitsha. South African Medical Journal, 91: 579-583.

Actuarial Society of South Africa (2004). ASSA2002 AIDS and Demographic Model. Available: http://www.assa.org.za/default.asp?id=1000000050

Badri M., Bekker L. G., Orrell C., et al. (2004). Initiating highly active antiretroviral therapy in sub-Saharan Africa: an assessment of the revised World Health Organization scaling-up guidelines. AIDS, 18, 8: 1159-1168.

Boily M., Bastos F. I., Desai K. and Mâsse B. (2004). Changes in the transmission dynamics of the HIV epidemic after the wide-scale use of antiretroviral therapy could explain increases in sexually transmitted infections. Sexually Transmitted Diseases, 31, 2: 100-113.

Bracher M., Santow G. and Cotts Watkins S. (2004). Assessing the potential of condom use to prevent the spread of HIV: a microsimulation study. Studies in Family Planning, 35, 1: 48-64.

Bradshaw D., Groenewald P., Laubscher R., et al. (2003). Initial burden of disease estimates for South Africa, 2000. South African Medical Journal, 93: 682-688.

Bradshaw D., Laubscher R., Dorrington R. E., et al. (2004). Unabated rise in number of adult deaths in South Africa. South African Medical Journal, 94, 4: 278-279.

Buvé A., Weiss H. A., Laga M., et al. (2001). The epidemiology of gonorrhoea, chlamydial infection and syphilis in four African cities. AIDS, 15, Suppl 4: S79S88.

Carpenter L. M., Kamali A., Ruberantwari A., et al. (1999). Rates of HIV-1 transmission within marriage in rural Uganda in relation to the HIV sero-status of the partners. AIDS, 13, 9: 1083-1089.

Collaborative Group on AIDS Incubation and HIV Survival (2000). Time from HIV-1 seroconversion to AIDS and death before widespread use of highly-active antiretroviral therapy: a collaborative re-analysis. Lancet, 355: 1131-1137.

Coutsoudis A., Pillay K., Spooner E., et al. (1999). Influence of infant-feeding patterns on early mother-to-child transmission of HIV-1 in Durban, South Africa: a prospective cohort study. Lancet, 354: 471-476. 
Dabis F., Msellati P., Meda N., et al. (1999). Six-month efficacy, tolerance, and acceptability of a short regimen of oral zidovudine to reduce vertical transmission of HIV in breastfed children in Cote d'Ivoire and Burkina Faso: a double-blind placebo-controlled multicentre trial. Lancet, 353: 786-792.

Davidse A. (2000). An analysis of the course of HIV infection using a Markov model. Thesis. Department of Statistics, University of Cape Town

De Cock K. M., Bunnell R. and Mermin J. (2006). Unfinished business - expanding HIV testing in developing countries. New England Journal of Medicine, 354, 5: 440-442.

De Vincenzi I. and European Study Group on Heterosexual Transmission of HIV (1994). A longitudinal study of human immunodeficiency virus transmission by heterosexual partners. New England Journal of Medicine, 331: 341-346.

Department of Health (1999). South Africa Demographic and Health Survey 1998: Full Report.

Department of Health (2001). National HIV and syphilis sero-prevalence survey of women attending public antenatal clinics in South Africa: 2000. Available: http://www.doh.gov.za/docs/index.html

Department of Health (2004). National HIV and syphilis antenatal sero-prevalence survey in South Africa 2003. Available: http://www.doh.gov.za/docs/index.html

Deschamps M., Fitzgerald D., Pape J. and Johnson W. (2000). HIV infection in Haiti: natural history and disease progression. AIDS, 14: 2515-2521.

Dorrington R. E. (2000). The ASSA2000 suite of models. Actuarial Society of South Africa Convention, 2000. Somerset West, South Africa. Available: www.assa.org.za/default.asp?id=1000000086.

Dorrington R. E., Johnson L. F. and Budlender D. (2004). ASSA2002 AIDS and Demographic models: User guide. Centre for Actuarial Research. Available: http://www.assa.org.za/default.asp?id=1000000050

Dorrington R. E., Moultrie T. A. and Timæus I. M. (2004). Estimation of mortality using the South African Census 2001 data. Centre for Actuarial Research. Monograph 11. Available: http://www.commerce.uct.ac.za/Research_Units/ CARE/

Downs A. and De Vincenzi I. (1996). Probability of heterosexual transmission of HIV: relationship to the number of unprotected sexual contacts. Journal of Acquired Immune Deficiency Syndromes, 11: 388-395. 
Eley B. (2005). Addressing the paediatric HIV epidemic: a perspective from the Western Cape Region of South Africa. Transactions of the Royal Society of Tropical Medicine and Hygiene, 100: 19-23.

Fideli U. S., Allen S. A., Musonda R., et al. (2001). Virologic and immunologic determinants of heterosexual transmission of human immunodeficiency virus type 1 in Africa. AIDS Research and Human Retroviruses, 17, 10: 901-910.

Fylkesnes K., Haworth A., Rosensvard C. and Kwapa P. M. (1999). HIV counselling and testing: overemphasizing high acceptance rates a threat to confidentiality and the right not to know. AIDS, 13, 17: 2469-2474.

Geffen N., Nattrass N. and Raubenheimer C. (2003). The cost of HIV prevention and treatment interventions in South Africa. Centre for Social Science Research. Working Paper 28. Available: http://www.cssr.uct.ac.za/pubs_cssr.html.

Glynn J. R., Sonnenberg P., Nelson G., et al. (2005). The effect of HIV on adult mortality: evidence from a large cohort of South African gold-miners with known dates of seroconversion and 10 years of follow-up. International Union for the Scientific Study of Population Conference. Tours, France, 18-23 July 2005.

Gray R., Wawer M., Brookmeyer R., et al. (2001). Probability of HIV-1 transmission per coital act in monogamous, heterosexual, HIV-1-discordant couples in Rakai, Uganda. Lancet, 357: 1149-1153.

Gray R. H., Li X., Wawer M. J., et al. (2003). Stochastic simulation of the impact of antiretroviral therapy and HIV vaccines on HIV transmission; Rakai, Uganda. AIDS, 17: 1941-1951.

Gregson S., Terceira N., Kakowa M., et al. (2002). Study of bias in antenatal clinic HIV-1 surveillance data in a high contraceptive prevalence population in subSaharan Africa. AIDS, 16: 643-652.

Guay L. A., Musoke P., Fleming T., et al. (1999). Intrapartum and neonatal single-dose nevirapine compared with zidovudine for prevention of mother-to-child transmission of HIV-1 in Kampala, Uganda: HIVNET 012 randomised trial. Lancet, 354: 795-802.

Hankins C., Tran T. and Lapointe N. (1998). Sexual behaviour and pregnancy outcome in HIV-infected women. Journal of Acquired Immune Deficiency Syndromes, 18: 479-487. 
Heuveline P. (2003). HIV and population dynamics: a general model and maximumlikelihood standards for East Africa. Demography, 40, 2: 217-245.

Hubert J., Burgard M., Dussaix E., et al. (2000). Natural history of serum HIV-1 RNA levels in 330 patients with a known date of infection. AIDS, 14: 123-131.

Human Sciences Research Council (2002). South African national HIV prevalence, behavioural risks and mass media household survey 2002.

Hussey G. D., Reijnhart R. M., Sebens A. M., et al. (1998). Survival of children in Cape Town known to be vertically infected with HIV-1. South African Medical Journal, 88, 5: 554-558.

Johnson L. F., Dorrington R. and Matthews A. (2006). An uncertainty analysis and sensitivity analysis of the ASSA2002 AIDS and Demographic model. Centre for Actuarial Research. Working paper. Available: http://www.commerce.uct.ac.za/ Research_Units/CARE/

Johnson L. F. and Dorrington R. E. (2001). The impact of AIDS on orphanhood in South Africa: a quantitative analysis. Centre for Actuarial Research. Available: http://www.commerce.uct.ac.za/Research_Units/CARE/

Jordan R., Gold L., Cummins C. and Hyde C. (2002). Systematic review and metaanalysis of evidence for increasing numbers of drugs in antiretroviral combination therapy. British Medical Journal, 324: 1-10.

Kassa E., Rinke de Wit T. F., Hailu E., et al. (1999). Evaluation of the World Health Organization staging system for HIV infection and disease in Ethiopia: association between clinical stages and laboratory markers. AIDS, 13: 381-389.

Korenromp E. L., Van Vliet C., Bakker R., et al. (2000). HIV spread and partnership reduction for different patterns of sexual behaviour - a study with the microsimulation model STDSIM. Mathematical Population Studies, 8, 2: 135173.

Longini I., Scott Clark W., Byers R., et al. (1989). Statistical analysis of the stages of HIV infection using a Markov model. Statistics in Medicine, 8: 831-843.

Maartens G., Wood R., O'Keefe E. and Byrne C. (1997). Independent epidemics of heterosexual and homosexual infection in South Africa - survival differences. Quarterly Journal of Medicine, 90: 449-454.

Malamba S., Morgan D., Clayton T., et al. (1999). The prognostic value of the World Health Organisation staging system for HIV infection and disease in rural Uganda. AIDS, 13: 2555-2562. 
Manzi M., Zachariah R., Teck R., et al. (2005). High acceptability of voluntary counselling and HIV-testing but unacceptable loss to follow up in a prevention of mother-to-child HIV transmission programme in rural Malawi: scaling-up requires a different way of acting. Tropical Medicine and International Health, 10, 12: $1242-1250$.

Marston M., Zaba B., Salomon J. A., et al. (2005). Estimating the net effect of HIV on child mortality in African populations affected by generalized HIV epidemics. Journal of Acquired Immune Deficiency Syndromes, 38, 2: 219-227.

McCoy D., Besser M., Visser R. and Doherty T. (2002). Interim findings on the national PMTCT pilot sites: lessons and recommendations. Health Systems Trust. Available: http://www.hst.org.za/publications/478.

McLeod H. D., Achmat Z. and Stein A. M. (2003). Minimum benefits for HIV/AIDS in South African medical schemes. South African Actuarial Journal, 3: 77-111.

Miotti P. G., Taha T. E. T., Kumwenda N. I., et al. (1999). HIV transmission through breastfeeding: a study in Malawi. Journal of the American Medical Association, 282, 8: 744-749.

Morgan D., Mahe C., Mayanja B., et al. (2002). HIV-1 infection in rural Africa: is there a difference in median time to AIDS and survival compared with that in industrialized countries? AIDS, 16: 597-603.

Morgan D., Mahe C., Mayanja B. and Whitworth J. (2002). Progression to symptomatic disease in people infected with HIV-1 in rural Uganda: prospective cohort study. British Medical Journal, 324: 193-196.

Murphy E., Collier A., Kalish L., et al. (2001). Highly active antiretroviral therapy decreases mortality and morbidity in patients with advanced HIV disease. Annals of Internal Medicine, 135: 17-26.

Myer L. (2005). Barrier methods. In S. S. Abdool Karim and Q. Abdool Karim, Eds. HIV/AIDS in South Africa. Cape Town: Cambridge University Press.

Nagelkerke N. J. D., Jha P., de Vlas S. J., et al. (2002). Modelling HIV/AIDS epidemics in Botswana and India: impact of interventions to prevent transmission. Bulletin of the World Health Organization, 80: 89-96.

Nduati R., John G., Mbori-Ngacha D., et al. (2000). Effect of breastfeeding and formula feeding on transmission of HIV-1: a randomized clinical trial. Journal of the American Medical Association, 283, 9: 1167-1174. 
Palella F., Delaney K., Moorman A., et al. (1998). Declining morbidity and mortality among patients with advanced human immunodeficiency virus infection. New England Journal of Medicine, 338: 853-860.

Peterman T. A., Stoneburner R. L., Allen J. R., et al. (1988). Risk of human immunodeficiency virus transmission from heterosexual adults with transfusionassociated infections. Journal of the American Medical Association, 259, 1: 5558.

Pilcher C. D., Tien H. C., Eron J. J., et al. (2004). Brief but efficient: acute HIV infection and the sexual transmission of HIV. Journal of Infectious Diseases, 189, 10: 1785-1792.

Plourde P. J., Pepin J., Agoki E., et al. (1994). Human immunodeficiency virus type 1 seroconversion in women with genital ulcers. Journal of Infectious Diseases, 170, 2: 313-317.

Quinn T., Wawer M., Sewankambo N., et al. (2000). Viral load and heterosexual transmission of human immunodeficiency virus type 1. New England Journal of Medicine, 342: 921-929.

Ramkissoon A., Kleinschmidt I., Beksinska M., et al. (2004). National Baseline Assessment of Sexually Transmitted Infection and HIV Services in South African Public Sector Health Facilities. Reproductive Health Research Unit, University of the Witwatersrand. Available: www.rhru.co.za/ images/Docs/6\%20proof\%20final15-01.pdf.

Reproductive Health Research Unit (2004). HIV and sexual behaviour among young South Africans: a national survey of 15-24 year olds. Joint publication of Reproductive Health Research Unit and loveLife. Available: www.rhru.co.za/images/Docs/national\%20survey\%20RHRU.pdf.

Robinson N. J., Mulder D. W., Auvert B. and Hayes R. J. (1995). Modelling the impact of alternative HIV intervention strategies in rural Uganda. AIDS, 9: 1263-1270.

Ross A., Van der Paal L., Lubega R., et al. (2004). HIV-1 disease progression and fertility: the incidence of recognized pregnancy and pregnancy outcome in Uganda. AIDS, 18: 799-804.

Røttingen J., Cameron D. W. and Garnett G. P. (2001). A systematic review of the epidemiological interactions between classic sexually transmitted diseases and HIV: how much is really known? Sexually Transmitted Diseases, 28: 579-597. 
Salomon J. A., Hogan D. R., Stover J., et al. (2005). Integrating HIV prevention and treatment: from slogans to impact. PLoS Medicine, 2, 1: e16.

Schneider H., Blaauw D., Dartnall E., et al. (2001). STD care in the South African private health sector. South African Medical Journal, 91: 151-156.

Scott V. E., Chopra M., Conrad L. and Ntuli A. (2005). How equitable is the scaling up of HIV service provision in South Africa? South African Medical Journal, 95, 2: 109-113.

Smith J. S. and Robinson N. J. (2002). Age-specific prevalence of infection with herpes simplex virus types 2 and 1: a global review. Journal of Infectious Diseases, 186, Suppl 1: S3-28.

Stover J. (2004). Projecting the demographic consequences of adult HIV prevalence trends: the Spectrum Projection Package. Sexually Transmitted Infections, 80, Suppl 1: i14-18.

Stover J., Walker N., Garnett G., et al. (2002). Can we reverse the HIV/AIDS pandemic with an expanded response? Lancet, 360: 73-77.

Terceira N., Gregson S., Zaba B. and Mason P. R. (2003). The contribution of HIV to fertility decline in rural Zimbabwe, 1985-2000. Population Studies, 57, 2: 149164.

Van der Ploeg C. P. B., Van Vliet C., De Vlas S., et al. (1998). STDSIM: a microsimulation model for decision support in STD control. Interfaces, 28: 84100 .

Van der Ryst E., Joubert G., Steyn F., et al. (2001). HIV/AIDS-related knowledge, attitudes and practices among South African military recruits. South African Medical Journal, 91: 587-591.

Voluntary HIV-1 Counselling and Testing Efficacy Study Group (2000). Efficacy of voluntary HIV-1 counselling and testing in individuals and couples in Kenya, Tanzania and Trinidad: a randomised trial. Lancet, 356: 103-112.

WHO International Collaborating Group for the study of the WHO Staging System (1993). Proposed 'World Health Organization staging system for HIV infection and disease': preliminary testing by an international collaborative cross-sectional study. AIDS, 7: 711-718.

Wiley J., Herschkorn S. and Padian N. (1989). Heterogeneity in the probability of HIV transmission per sexual contact: the case of male-to-female transmission in penile-vaginal intercourse. Statistics in Medicine, 8: 93-102. 
Williams B., Gilgen D., Campbell C., et al. (2000). The natural history of HIV / AIDS in South Africa: A biomedical and social survey in Carletonville. Johannesburg: Council for Scientific and Industrial Research

Wilson T. E., Gore M. E., Greenblatt R., et al. (2004). Changes in sexual behaviour among HIV-infected women after initiation of HAART. American Journal of Public Health, 94, 7: 1141-1146. 
Johnson \& Dorrington: Modelling the demographic impact of HIV/AIDS in South Africa 